\title{
Employment Horizon and the Choice of Performance Measures: Empirical Evidence from Annual Bonus Plans of Loss-Making Entities
}

\author{
Michal Matějka \\ R̂́1ss School of Business, University of Michigan, Ann Arbor, Michigan 48109, \\ matejka@umich.edu \\ Kenneth A. Merchant \\ Leventhal School of Accounting, University of Southern California, Los Angeles, California 90089, \\ kmerchan@marshall.usc.edu \\ Wim A. Van der Stede \\ London School of Economics and Political Science, London WC2A 2AE, United Kingdom, \\ w.van-der-stede@lse.ac.uk
}

\begin{abstract}
W e examine the extent to which employment horizon concerns affect the relative emphasis on financial versus nonfinancial performance measures in annual bonus plans. We argue that managers of loss-making firms are likely to voluntarily or forcibly depart in the near future and, consequently, have a shorter employment horizon. Loss-making firms then need to increase the emphasis on forward-looking nonfinancial performance measures to motivate long-term effort of their managers. Thus, we hypothesize that the emphasis on nonfinancial performance measures is greater in loss making than in profitable firms even after controlling for the informativeness of earnings. We find consistent support for our hypothesis using different (archival, survey, and field) data sources and various proxies for short employment horizon and the emphasis on nonfinancial performance measures.
\end{abstract}

Key words: $\mathbf{A 2}$ employment horizon problem; performance measurement; losses; bonus plans

History: Received July 18, 2006; accepted December 20, 2008, by Stefan Reichelstein, accounting. Published online in Articles in Advance.

\section{Introduction}

A fundamental question in accounting research concerns the choice of performance measures for evaluating executives. Although firms have traditionally relied on financial metrics to evaluate performance, there has been an increase in the use of nonfinancial performance measures (Ittner et al. 1997). Prior literature shows that nonfinancial performance can compensate for "noise" and "goal incongruence" of financial performance measures (e.g., Datar et al. 2001, Feltham and Xie 1994, Banker and Datar 1989). There is also a stream of work examining the choice of performance measures in multiperiod agency settings (Şabac 2007; Dutta and Reichelstein 2002, 2005; Sliwka 2002). This literature maintains that another desirable contracting attribute of nonfinancial measures is their ability to predict future performance and to facilitate intertemporal matching between current investments and future returns. If managers have a short employment horizon, particularly, it is difficult to motivate long-term effort without the reliance on some forward-looking performance measures (Dutta and Reichelstein 2003, Dikolli 2001).
Despite the extensive theoretical work in this area, there is little empirical evidence in support of the contracting benefits of forward-looking performance measures in the presence of employment horizon concerns. Although there is prior literature examining sensitivity of CEO compensation to (forward-looking) stock returns as CEOs approach retirement (Dikolli et al. 2003, Bryan et al. 2000, Yermack 1995, Gibbons and Murphy 1992), the results are mixed, possibly because stock compensation itself may be a source of managerial myopia (McAnally et al. 2008, Cheng and Warfield 2005) or, alternatively, CEO concerns about postretirement board service may alleviate the horizon problem (Brickley et al. 1999).

Our study differs from this literature in two important ways. First, we examine how compensation linked to nonfinancial performance measures (rather than stock returns) alleviates employment horizon issues. Second, we tap a novel empirical setting to identify firms with severe employment horizon problems. We build on prior literature suggesting that firms commonly report losses for a number of consecutive periods (Skinner and Soltes 2008, Joos and 
Plesko 2005). We argue (and corroborate with our data) that firms with several consecutive losses are characterized by high management turnover and, consequently, short-lived executive employment contracts. Our tests compare the choice of performance measures in firms with one to five consecutive loss years (and a high likelihood of CEO turnover) to a control group of highly profitable firms where employment horizon issues are less severe. We predict that the emphasis on nonfinancial performance measures is greater in settings where the employment horizon is shorter.

We first estimate an empirical model of the likelihood of CEO turnover as a function of prior profit/loss history and other proxies for employment horizon such as proximity to normal retirement, stock ownership, and the CEO being the chairman/founder of the firm. We find that the probability of CEO departure is higher in loss-making firms and when CEOs approach normal retirement. The probability of departure is lower when CEOs hold more of their firm's stock or when they have served as their company's chairman for 10 or more years. Predicted values from this model then reflect the ex ante probability of CEO turnover, which we use as an aggregate proxy for short employment horizon. Consistent with our main hypothesis, we find a significant positive association between this proxy and the use of nonfinancial performance measures even after controlling for differences in informativeness of financial performance measures and differences in the length of executive compensation disclosures (which we rely on to identify whether firms use nonfinancial performance measures).

To address the limitations of our archival data solely based on firms' proxy statement disclosures of their use of nonfinancial measures, we collect additional field and survey data containing detailed information on how different entities weigh the importance of nonfinancial measures for performance evaluation purposes. Based on our field study insights, we construct three different proxies for emphasis on nonfinancial performance measures (emphasis on nonfinancial measures in overall evaluations, in bonus plan formulas, and the extent to which performance evaluations are subjective). We find robust support for our main hypothesis using a sample of 141 profitable and loss-making entities participating in our survey. Specifically, loss-making entities expecting losses to persist and entities concerned about managerial retention (i.e., entities where employment horizon is likely to be short) are significantly more likely to emphasize nonfinancial performance measures.

Our findings make three contributions to the literature. First, to our knowledge, our study is the first empirical examination of how firms use nonfinancial performance measures to alleviate employment horizon issues. We find evidence consistent with the theory that forward-looking performance measures reduce agency costs and facilitate motivation of longterm effort when agents have short employment horizons (Dikolli 2001). Second, we replicate and extend several findings of Ittner et al. (1997) regarding the choice of performance measures and their relative informativeness. We find that profit urgency and financial distress (which make financial performance measures more congruent with firm goals) are associated with a lower emphasis on nonfinancial performance measures, a result that Ittner et al. (1997) failed to empirically support. At the same time, we show that informativeness of earnings is unlikely to account for all the difference in the emphasis on nonfinancial performance measures between loss-making and profitable entities because the difference persists even after including common controls for noise and congruence of earnings. Finally, our findings help explain why the relationship between earnings and cash compensation disappears when earnings are negative (Leone et al. 2006, Gaver and Gaver 1998, Sloan 1993, Lambert and Larcker 1987). Greater emphasis on nonfinancial measures in loss-making entities implies a weaker link between earnings and cash compensation, assuming nonfinancial performance measures are imperfectly contemporaneously correlated with earnings.

The next section reviews the prior literature. Section 3 describes our archival data and discusses the main results, additional evidence, and various robustness tests. Section 4 presents additional insights based on our field and survey data. The last section summarizes and concludes.

\section{Prior Literature and Hypothesis}

It is well established that the emphasis placed on a performance measure for evaluation purposes should be greater when other measures are relatively more noisy (Banker and Datar 1989). The emphasis on a measure should also be greater if it increases the degree of congruence between firm value and the overall performance indicator of its manager (Datar et al. 2001, Lambert 2001, Baker 2000, Feltham and Xie 1994). Ittner et al. (1997) provide empirical evidence on the relative weights placed on financial and nonfinancial performance measures in CEO bonus contracts that is largely consistent with these theoretical predictions.

A related stream of theoretical work examines dynamic issues related to the choice of performance measures in multiperiod agency models. This literature highlights a demand for intertemporal matching 
between current investment and future returns; i.e., a demand for forward-looking measures capturing how managers' current actions affect future value of the firm (Şabac 2007; Dutta and Reichelstein 2005, 2002). Specifically, Dutta and Reichelstein (2003) argue that, in the absence of a long-term commitment, it is crucial for employment contracts to include some forwardlooking measures to generate investment incentives in the current period. Dikolli (2001) shows that the relative emphasis placed on forward-looking performance measures increases as the agent's employment horizon decreases. The intuition is that an agent who is likely to leave in the next period has weak incentives to exert long-term effort (which is costly now and generates benefits in the future) unless this effort can be rewarded with same-period compensation based on forward-looking measures.

Empirically, there is evidence that firm investment responds to the choice of performance measures in executive compensation contracts (Balachandran 2006). Specifically addressing employment horizon issues, Dechow and Sloan (1991) find that CEOs spend less on research and development (R\&D) during their final years in office, whereas Cheng (2004) shows that stock option grants to CEOs approaching retirement can mitigate opportunistic reductions in $R \& D$ spending. Related to these findings, a stream of literature examines whether sensitivity of CEO compensation to stock returns (a forward-looking measure of performance) increases as CEOs approach retirement (Dikolli et al. 2003, Bryan et al. 2000, Yermack 1995, Gibbons and Murphy 1992, Lewellen et al. 1987). The results are mixed possibly because of inefficiencies in how stock-based incentives balance short-term and long-term managerial effort-stock compensation itself may be a source of managerial myopia (McAnally et al. 2008, Erickson et al. 2006, Cheng and Warfield 2005), and nonfinancial performance measures can induce a desirable allocation of management effort between the short term and long term more efficiently than the stock price can (Dikolli and Vaysman 2006).

We contribute to this literature by examining how the employment horizon problem affects the emphasis placed on nonfinancial performance measures in executive compensation. Although the forwardlooking nature of nonfinancial measures is well recognized (Nagar and Rajan 2005, Sliwka 2002, Banker et al. 2000), there is hardly any empirical evidence on the use of nonfinancial performance measures to mitigate employment horizon issues. As an exception, Farrell et al. (2008) provide experimental evidence that incentive contracts incorporating quality as a performance measure increase long-term efforts and that this effect is stronger for subjects with short employment horizon than for subjects with long employment horizon. Summarizing the foregoing discussion, we predict the following:

HyротнеSis 1. The emphasis on nonfinancial performance measures is greater in settings where the employment horizon is shorter.

Tests of Hypothesis 1 based on publicly available data face several empirical challenges related to measurement of the main constructs. The first challenge is that proxies for severity of the employment horizon problem based on proximity to normal retirement age may be weaker than previously thought because concerns about postretirement board service are an important source of CEO performance incentives in the final years before retirement (Brickley et al. 1999). Moreover, the decision of which performance measures to include in incentive contracts is a structural choice unlikely to change from year to year (Jensen and Meckling 1992). Given this persistence in performance measure choices, a test of Hypothesis 1 necessitates a setting where employment horizon issues are also persistent from year to year.

To identify such a setting, we rely on prior literature documenting that CEO turnover is more likely to occur in loss-making than in profitable firms (e.g., Huson et al. 2001) and that it has become increasingly common for firms to report several consecutive losses (Joos and Plesko 2005, Hayn 1995). In addition, Joos and Plesko (2005) find that the longer the consecutive loss sequence the higher the ex ante expected probability of another loss. Thus, we expect that the likelihood of a voluntary or forced CEO departure is increasing in the number of consecutive loss years. It follows that CEOs in firms with consecutive loss years have a persistently shorter employment horizon than CEOs in highly profitable firms experiencing little turnover (we discuss corroborative evidence in \$3.4). ${ }^{1}$

The second challenge when testing Hypothesis 1 with publicly available data is that proxies for the emphasis on nonfinancial performance measures hinge on the quality of firms' disclosures about the design of executive incentive contracts. Moreover, prior literature suggests that firms use disclosures to strategically manage the perception of their earnings and that the amount and quality of disclosure depends on firm performance (Rogers and Stocken 2005, Miller 2002, Schrand and Walther 2000, Frost 1997). Whereas we

\footnotetext{
${ }^{1}$ The failure to achieve long-term sustainable results can be either due to poor management or due to adverse environmental factors uncontrollable by management. In the former case, the board of directors is likely to replace the CEO, whereas in the latter case, the $\mathrm{CEO}$ is likely to search for an alternative (more rewarding) employment opportunity. Thus, regardless of the cause, firms with consecutive losses are more likely to suffer from employment horizon issues than firms that deliver sufficiently large returns.
} 
are not aware of any study specifically addressing disclosures regarding executive compensation, ${ }^{\mathrm{A}} \mathrm{Li}$ (2008) provides evidence that annual reports of loss-making firms are longer. A plausible explanation is that managers of poorly performing firms are more likely to offer explanations for their poor earnings and blame external factors beyond their control (Hutton et al. 2003, Baginski et al. 2000).

Despite novel features of our archival research design (described in more detail in the next section), any test solely based on publicly available data is bound to be imperfect. Therefore, we also collect field and survey data (described in \$4) to corroborate that our results based on archival data are not unduly influenced by imperfect measurement of our main constructs.

\section{Archival Data}

\subsection{Sample Selection}

As discussed above, a test of Hypothesis 1 requires a setting where some firms have an ex ante high likelihood of a departure of a key executive (CEO) and, consequently, face an employment horizon problem. In this study, we use the number of consecutive loss years as a proxy for such ex ante likelihood of CEO turnover (Joos and Plesko 2005, Huson et al. 2001). ${ }^{2}$ Therefore, we select loss-making firms with one to five consecutive loss years based on the rationale (which we corroborate empirically) that firms with repeated losses are likely to suffer to an increasing extent from the employment horizon problem. We match these loss-making firms with a sample of clearly profitable firms (with five years of positive earnings and average return on equity greater than $10 \%$ ). We use highly profitable firms as the control group conjecturing that firms with positive but low returns may face similar employment horizon issues as loss-making firms. To corroborate this conjecture, we separately consider profitable firms excluded from our control group (i.e., firms with five years of positive earnings but average return on equity of $10 \%$ or less).

\footnotetext{
${ }^{2}$ Prior literature commonly uses three types of earnings thresholds as an indication of underperformance: losses, earnings decreases, and failure to meet analysts' forecasts (DeGeorge et al. 1999, Burgstahler and Dichev 1997). Given that the selection of performance measures for incentive contracts is a structural choice unlikely to change from year to year, we use zero earnings as a threshold because losses tend to be serially correlated and several consecutive loss years may warrant redesigning incentive contracts. In contrast, prior earnings and analysts' forecasts are "moving targets" and failure to achieve them is not necessarily correlated over time, which makes these thresholds less suited for identification of firms suffering from a persistent employment horizon problem. Nevertheless, $\S 3.5$ uses the number of earnings decreases and the number of missed annual earnings forecasts during 1997-2001 as control variables to check the robustness of our results.
}

Specifically, in the first stage, we sample from the Compustat population of firms with negative earnings per share (EPS) in 2001, sales over $\$ 10$ million, and a loss pattern falling into one of the following: (i) a loss in 2001 and profits in each year from 1997 to 2000 (LOSS1: 405 firms in the population); (ii) losses in 2000-2001 and profits in 1997-1999 (LOSS2: 228 firms); (iii) losses in 1999-2001 and profits in 1997-1998 (LOSS3: 151 firms); (iv) losses in 1998-2001 and a profit in 1997 (LOSS4: 142 firms); and (v) losses in 1997-2001 (LOSS5: 420 firms). We retain all firms in the LOSS3 and LOSS4 groups (151 and 142 firms, respectively) and randomly select firms in the other groups. Excluding firms with missing 2001 proxy statement information yields a sample of 500 loss-making firms. We further exclude 31 firms $(6 \%)$ that have no annual bonus plans and typically offer only salary and longterm (typically equity-based) compensation to their CEOs. The final sample consists of 469 firms: 92, 93, 100, 85, and 99 firms in the LOSS1-LOSS5 groups, respectively. ${ }^{3}$

In the second stage, we obtain a sample of highly profitable firms (PROF_H) defined as Compustat firms with sales over $\$ 10$ million, positive EPS in each year, and an average ratio of earnings (as in EPS) to shareholder equity during 1997-2001 exceeding 10\% (a population of 1,707 firms). We select a random sample of these firms stratified by three-digit SIC codes to match the industry composition of the loss-making sample of 500 firms. After excluding firms with missing proxy statement information, we obtain a sample of 307 profitable firms out of which 295 (96\%) offer their CEOs annual bonuses.

Finally, in the third stage, we sample firms from the Compustat population with low profitability (PROF_L) defined as the profitable group above except that the average return on equity during 1997-2001 is below $10 \%$ (615 firms). We select a random sample of 140 firms stratified by industry. ${ }^{4}$ After excluding firms with missing information, we obtain 109 firms with low profitability out of which 105 (96\%) offer their CEOs annual bonuses. Thus, the total combined sample consists of 869 firms with annual bonus plans

\footnotetext{
${ }^{3}$ The likelihood that losses persist into the future increases with the number of consecutive loss years. In firms with multiple consecutive loss years, even newly appointed CEOs (who cannot be blamed for past losses) are more likely to face uncertain prospects and to (voluntarily or forcibly) depart than in profitable firms. To maximize the power of our tests, our sampling procedure excludes firms that do not have a clear pattern of consecutive loss years during 1997-2001 (e.g., a loss-making firm turning profitable and then loss-making again).

${ }^{4}$ We aimed for a sample of PROF_L firms similar in size to the samples of LOSS1-LOSS5 firms. For PROF_H firms (our main control group), we aimed for a sample no less than half the total number of all loss-making firms. The final size of these samples was ultimately also determined by the industry matching procedure.
} 
(469 loss-making firms, 295 highly profitable firms, and 105 firms with low profits).

We collect data on CEO turnover to verify that lossmaking firms with a higher number of consecutive loss years are more likely to experience voluntary or forced departure of executives, i.e., suffer more from the employment horizon problem. As expected, we find that the proportion of firms that experienced CEO turnover at least once during the 1997-2001 period is increasing in the number of consecutive loss years. The proportion (untabulated) is 39\% in PROF_H firms, $35 \%$ in PROF_L firms, $34 \%$ in LOSS1 firms, $49 \%$ in LOSS2 firms, $53 \%$ in LOSS3 firms, 55\% in LOSS4 firms, and $57 \%$ in LOSS5 firms (using a two-sample $t$-test with unequal variances we find that the average proportion in profitable firms is significantly lower than the average in loss-making firms; $p<0.01$ ).

\subsection{Variable Measurement}

We construct a proxy for the emphasis on nonfinancial performance measures using public data from firms' proxy statement disclosures.

Emphasis placed on nonfinancial performance measures (NONFIN). We code a dummy variable NONFIN that equals one if the 2001 proxy statement disclosure pertaining to the CEO's annual bonus explicitly mentions at least one of the following: (i) "nonfinancial" or "qualitative" measures; (ii) financial and other performance measures (e.g., financial and operational performance); (iii) nonfinancial and "hard-to-quantify" performance dimensions (such as leadership, recruiting of employees, vision, or work ethic); or (iv) individual performance measures as determinants of CEO compensation. Section 3.5 shows that alternative coding choices do not materially affect our conclusions.

Next, we capture differences in employment horizon by comparing firms with consecutive loss years to a control group of profitable firms as described in the previous section. We also include three additional variables that are likely to correlate with the likelihood of CEO departure in the near future (and thus proxy for employment horizon). For each of the three variables below, most of the data are hand-collected from firms' proxy statements, but whenever available, we use data from Execucomp.

$C E O$ age $(A G E)$. Prior literature commonly uses proximity to normal retirement age as a proxy for short employment horizon (Brickley et al. 1999, Gibbons and Murphy 1992, Dechow and Sloan 1991). Following this literature, we define $A G E$ as a dummy variable equal to one if the CEO is 60 years of age or older in 2001 (using 62 or 65 as alternative cutoffs does not materially affect the results).

CEO stock ownership (PSHO). Prior studies (Cheng et al. 2005, Chen 2004, Morck et al. 1988) argue that ownership stakes disproportionately increase managerial influence and yield substantial benefits of entrenchment (such as a reduced likelihood of dismissal). Entrenchment benefits also reduce the likelihood of a voluntary departure because they make an alternative offer from a firm where the CEO does not own stock less attractive. Moreover, a high ownership stake may proxy for accumulated nonvested equity grants the CEO might have to forgo when leaving the firm. Thus, we expect that higher CEO share ownership reduces the likelihood of both voluntary and forced CEO departure. We define PSHO as the log (to reduce deviations from normality) of the percentage of shares owned by the CEO in 2000, i.e., just prior to designing 2001 compensation (whenever available, we use Execucomp item SHROWNPC or, if missing, calculate it from SHROWN and SHRSOUT).

CEO as the chairman/founder (CHAIR). Some CEOs have a prominent position within their firms as founders and/or long-time chairmen of the board of directors. These CEOs are more likely than others to stay in their jobs either due to entrenchment or because their talent and expertise are deemed indispensable to the firm. CHAIR equals one if the CEO (i) has been a chairman for 10 or more years in 2001 (using 5 or 15 years as cutoffs does not materially affect the results), or (ii) has been chairman since the $\mathrm{AP} \mathrm{O}$ (first year of data available on Compustat) taking place 5 to 10 years prior to 2001 .

When testing our hypothesis, it is important to control for determinants of performance measurement practices unrelated to employment horizon issues. Ittner et al. (1997) predict and find that several proxies for informativeness of financial performance measures are negatively related to the emphasis on nonfinancial performance measures. We follow Ittner et al. (1997) when constructing the following seven informativeness proxies from Compustat data: (i) financial distress (FSTRESS), a dummy variable equal to one if the bankruptcy proxy of Ohlson (1980) exceeds its critical value in at least one of the years 1997-2001,5 (ii) market to book (MTB), the average of marketto-book ratios during 1997-2001; (iii) RED-to-sales (REDS) ratios averaged over the five years 1997-2001; (iv) employees-to-sales (EMPS) ratios averaged over the five years 1997-2001; (v) value relevance of earnings (CORR), firm-level correlation between current stock market returns and accounting returns in the previous quarter (changes in EPS scaled by beginningof-period stock price) estimated using quarterly data

\footnotetext{
${ }^{5}$ We set FSTRESS to zero by default for highly profitable firms and for firms with five consecutive loss years because the Ohlson (1980) model does not fully incorporate all past profits/losses. The latter group (LOSS5) largely consists of firms with no or negligible profits since IPO and substantial R\&D expenses (the average R\&Dto-sales ratio is 0.37 , compared with 0.03 in PROF_H or 0.09 in LOSS4 firms). Thus, it is reasonable to assume that LOSS5 firms are start-up rather than distressed firms, even though the Ohlson model predicts $83 \%$ of them face bankruptcy.
} 
from 1997-2001; (vi) volatility in industry profitability $(S T D M)$, a factor score reflecting standard deviation in median industry (defined by three-digit SIC codes) accounting returns (return on assets, equity, and sales) during 1997-2001; and (vii) regulation (REGUL), a dummy variable coded one if firms operate in SIC codes 481, 491,492, 493, or 494 (telecom or utilities).

Furthermore, we control for the amount of disclosure in the executive compensation section of firms' proxy statements. Poor performance can give rise to lengthy discussions of executive compensation issues, which may increase the likelihood of disclosing the use of nonfinancial performance measures. To control for this effect, we calculate DISCLOSE as the log of the number of words in the proxy statement section typically entitled "Report of the Compensation Committee of the Board of Directors on Executive Compensation." Specifically, we rely on the Microsoft Office Word 2003 word count function to count the number of words below the title and above the signature (excluding compensation tables).

Finally, we control for size (MSIZE), by taking the $\log$ of market value at the end of 2001, and firm age (FIRMAGE), measured as the number of years for which data is available from Compustat for the period 1980-2001. We also collect data on CEO turnover (TURN), which we use to validate our proxies for short employment horizon. TURN equals one if a firm had a new CEO for most of the year 2001 or 2002 (we use Execucomp data when available and hand-collect turnover data from proxy statements when it is not).

\subsection{Descriptive Statistics}

Online Appendix A in the e-companion reports relevant descriptive data specific to each of the different groups of firms in our sample. ${ }^{6}$ We find that $37 \%$ $(32 \%)$ of the firms with high (low) profitability use some type of nonfinancial performance measures in annual CEO bonus plans. For loss-making firms, this percentage increases monotonically with the number of consecutive loss years: $30 \%, 31 \%, 42 \%, 44 \%$, and $61 \%$ in LOSS1-LOSS5 firms, respectively. Consistent with the evidence presented earlier, the likelihood of CEO turnover in 2001 or 2002 is also higher on average $(p<0.01)$ in loss-making $(26 \%, 28 \%, 30 \%, 24 \%$, and $31 \%$ in LOSS1-LOSS5 firms, respectively) than in profitable (15\% in PROF_H and $20 \%$ in PROF_L) firms.

Not surprisingly, loss-making firms are younger, and more likely to experience financial distress and to operate in industries with higher volatility of earnings than profitable firms. Also, our profitable firms

\footnotetext{
${ }^{6}$ An electronic companion to this paper is available as part of the online version that can be found at http://mansci.journal.informs. org/.
}

are larger than the loss-making firms. The median market value (MSIZE) in firms with high (low) profitability is $\$ 950$ (\$382) million, whereas the median market value of our groups of loss-making firms ranges from $\$ 29$ to $\$ 133$ million. The difference in size arises because we match profitable firms to our sample of loss-making firms by industry classification only. Many industries (at the SIC-3 code level) do not have a sufficient number of firms to allow matching on both industry and size. Therefore, we control for differences in size by including MSIZE (log of market value of equity) in our regressions. Table A8 in Online Appendix A provides more details on industries (SIC-3 codes) represented with at least 10 observations in our sample (it also includes averages of NONFIN and TURN by industry).

\subsection{Hypothesis Test}

Our hypothesis predicts that firms are more likely to use nonfinancial performance measures when their CEO's employment horizon is shorter. As discussed earlier, we use several proxies for short employment horizon: the number of consecutive loss years (LOSS1-LOSS5), a dummy variable equal to one for firms where the CEO is 60 or older $(A G E)$, the percentage of shares owned by the CEO (PSHO), and a dummy variable equal to one if the $\mathrm{CEO}$ has been chairman for 10 or more years (CHAIR). Ultimately, however, the validity of these proxies hinges on their ability to predict CEO turnover.

We expect that all groups of loss-making firms (LOSS1-LOSS5) and possibly firms with low profitability (PROFIT_L) have an increased probability of CEO turnover relative to the benchmark in highly profitable firms (PROF_H). We also expect that CEOs that are over 60 years old in 2001 (AGE) are more likely to retire in 2001 or 2002 than other executives (consistent with this rationale, we code $A G E$ based on the age of the departing CEO when turnover took place in 2001). Following prior literature suggesting that the correlation between CEO age and turnover is weaker in firms experiencing forced turnover (Engel et al. 2003), we also include an interaction term $A G E$. $P R O F \_H$ to allow the effect of CEO age to vary across highly profitable and other groups of firms. Finally, we expect that when CEO stock ownership is high (PSHO) or when the CEO is the chairman and/or founder (CHAIR) the probability of turnover is lower.

To validate our proxies for short employment horizon, we therefore estimate the following logit model of the probability of CEO turnover in 2001 or 2002:

$$
\begin{aligned}
& \text { TURN } \\
& \begin{aligned}
= & \gamma_{00}+\gamma_{01} \text { PROF_L }+\sum_{j=1}^{5} \gamma_{j} \text { LOSS }_{j}+\gamma_{6} \text { AGE } \\
& +\gamma_{7} \text { AGE } \cdot \text { PROF_H }+\gamma_{8} P S H O+\gamma_{9} \text { CHAIR }+\omega .
\end{aligned}
\end{aligned}
$$


Logit Estimation of the Likelihood of CEO Turnover

\begin{tabular}{|c|c|c|}
\hline & \multicolumn{2}{|c|}{ TURN } \\
\hline & Coefficient & $p$-value \\
\hline Intercept & $-2.819^{* * *}$ & 0.000 \\
\hline PROF_L & $1.402^{* * *}$ & 0.002 \\
\hline LOSS1̄ & $1.625^{* * *}$ & 0.001 \\
\hline LOSS2 & $1.822^{* * *}$ & 0.000 \\
\hline LOSS3 & $2.273^{* * *}$ & 0.000 \\
\hline LOSS4 & $1.831^{* * *}$ & 0.000 \\
\hline LOSS5 & $2.475^{* * *}$ & 0.000 \\
\hline$A G E$ & $0.065^{* *}$ & 0.022 \\
\hline AGE. PROF_H & $1.689^{* * *}$ & 0.001 \\
\hline PSHO & $-0.223^{* * *}$ & 0.000 \\
\hline CHAIR & $-1.143^{* * *}$ & 0.001 \\
\hline Pseudo $R^{2}$ & & \\
\hline Correctly classified & & \\
\hline$N$ & & \\
\hline \multicolumn{3}{|c|}{$\begin{array}{l}\text { NOtes. TURN, CEO turnover in } 2001 \text { or } 2002 \text {; PROF_L, firms profitable during } \\
\text { 1997-2001 with average return on equity lower than } 10 \% \text {; LOSS1-LOSS5, } \\
\text { loss-making firms with one to five consecutive loss years; AGE, dummy vari- } \\
\text { able for firms where the CEO's age is } 60 \text { years or greater; PROF_H, highly } \\
\text { profitable firms; PSHO, log of the percentage of shares owned by the CEO at } \\
\text { the beginning of } 2001 \text {; CHAIR, dummy variable for firms where the CEO has } \\
\text { also been a chairman for } 10 \text { or more years. } \\
\text { ***, } * * \text { * Significant at the } 0.01 \%, 0.05 \% \text {, and } 0.10 \% \text { levels, respectively } \\
\text { (two-tailed). }\end{array}$} \\
\hline
\end{tabular}

Table 1 presents the results of estimating Equation (1) after excluding firms with CEO turnover in 2000 because a model of the likelihood of CEO departure within a year of being appointed is likely to be different from the general model.

We find strong evidence that our empirical proxies for employment horizon are associated with CEO turnover. Specifically, firms with low profitability and all groups of loss-making firms are significantly more likely to experience turnover than highly profitable firms $(p<0.01)$. Our results show that the estimated coefficients increase monotonically (except for LOSS4 firms) with the number of consecutive loss years. Other proxies for short employment horizon also have a significant effect in the predicted direction. AGE is positively associated with CEO turnover and this association is stronger in highly profitable firms, as suggested by prior literature $(p<0.01$ for highly profitable firms, and $p=0.02$ for all other firms). A greater percentage of shares owned by a CEO decreases the probability of turnover $(p<0.01)$ and so does the fact that a CEO has been the long-time chairman $(p<0.01)$.

When testing Hypothesis 1, we rely on the above estimation results to calculate the predicted probability of CEO turnover (PR_TURN) as an aggregate proxy for short employment horizon. In particular, we specify a logit model of the probability that a firm uses nonfinancial performance measures in 2001 (NONFIN) as a function of (i) the probability that the CEO leaves the firm in the near future (PR_TURN),
Table 2 Logit Estimation of the Likelihood of Using Nonfinancial Performance Measures in Annual Bonus Plans

\begin{tabular}{|c|c|c|}
\hline & \multicolumn{2}{|c|}{ NONFIN } \\
\hline & Coefficient & $p$-value \\
\hline Intercept & $-3.322^{* *}$ & 0.018 \\
\hline PR_TURN & $1.733^{* *}$ & 0.017 \\
\hline FSTRESSS & $-0.617^{* *}$ & 0.020 \\
\hline MTB & 0.000 & 0.992 \\
\hline$R \& D S$ & $2.964^{* * *}$ & 0.000 \\
\hline EMPS & -12.421 & 0.350 \\
\hline CORR & $-1.150^{* *}$ & 0.047 \\
\hline STDM & $0.250^{* *}$ & 0.015 \\
\hline REGUL & $1.158^{*}$ & 0.089 \\
\hline DISCLOSE & $0.410^{*}$ & 0.055 \\
\hline FIRMAGE & $-0.028^{*}$ & 0.081 \\
\hline MSIZE & 0.035 & 0.054 \\
\hline Pseudo $R^{2}$ & \multicolumn{2}{|c|}{0.11} \\
\hline Correctly classified & \multicolumn{2}{|c|}{$68 \%$} \\
\hline$N$ & \multicolumn{2}{|c|}{555} \\
\hline
\end{tabular}

Aotes. NONFIN, Dummy variable for the use of nonfinancial performance measures in CEO 2001 bonus plan; PR_TURN, predicted values (probabilities) of CEO turnover based on coefficients in Table 1; FSTRESS, dummy variable for financial-distress firms; MTB, market-to-book ratio (averaged over 1997-2001); R\&DS, research and development expenses divided by sales (averaged); EMPS, number of employees divided by sales (averaged); CORR, correlation between stock returns and prior quarter accounting returns; STDM, volatility in median industry profitability (factor score); REGUL, regulated industries (SIC-3: 481, 491, 492, 493, 494); DISCLOSE, log of the number of words in the proxy statement discussion of executive compensation; FIRMAGE, number of years with Compustat data during 1980-2002; $M S I Z E$, log of the market value of the firm (\$ millions). Industry dummies (three-digit SIC codes) used in a stepwise estimation procedure; SIC-382 and SIC-386 retained as the only significant effects but not reported above.

${ }^{* * *},{ }^{* *},{ }^{*}$ Significant at the $0.01 \%, 0.05 \%$, and $0.10 \%$ levels, respectively (two-tailed).

(ii) several proxies for informativeness of financial performance measures described earlier, (iii) a control variable for the amount of disclosure regarding executive compensation (DISCLOSE), and (iv) other controls including firm age (FIRMAGE) and size (MSIZE):

$$
\begin{aligned}
& \text { NONFIN } \\
& \begin{aligned}
= & \beta_{0}+\beta_{1} P R \_T U R N+\beta_{2} \text { FSTRESS }+\beta_{3} M T B+\beta_{4} R \& D S \\
& +\beta_{5} \text { EMPS }+\beta_{6} \text { CORR }+\beta_{7} \text { STDM }+\beta_{8} R E G U L \\
& +\beta_{9} D I S C L O S E+\beta_{10} \text { FIRMAGE }+\beta_{11} M S I Z E+\varepsilon .
\end{aligned}
\end{aligned}
$$

Table 2 presents the results of estimating Equation (2) after excluding firms with CEO turnover in 2000 or 2001 because performance measures and incentive arrangements for CEOs in the first or last year on the job are unlikely to be representative.

Consistent with our hypothesis, we find that the probability of CEO departure in the near future (PR_TURN) is significantly and positively associated with the use of nonfinancial performance measures in annual bonus plans $(p=0.02)$. Thus, firms with a higher predicted probability of CEO turnover due to 
several consecutive years of losses and/or the CEO approaching retirement or having less power over the board are more likely to disclose in their proxy statements that their CEO's short-term incentive plan includes nonfinancial measures of performance.

In addition, several of our control variables have significant predictive power. Consistent with Ittner et al. (1997), we find that nonfinancial performance measures are more prevalent in firms where the R\&Dto-sales ratio is high $(p<0.01)$, where the correlation between stock returns and EPS (CORR) is low $(p=0.05)$, or where volatility in median industry profitability $(S T D M)$ is high $(p=0.02)$. In addition, we find that firms in financial distress are less likely to use nonfinancial performance measures $(p=0.02){ }^{7}$ This latter result is consistent with a prediction of Ittner et al. (1997) for which, however, they did not find empirical support. We do not find a significant effect of the market-to-book ratio, a proxy for growth strategy, possibly due to the difficulty of calculating MTB in loss-making firms (some of which have negative book values). The insignificant result regarding the employees-to-sales ratio may be due to the fact that EMPS may proxy both for firm strategy and for inefficiencies (the latter effect possibly being more important in our sample). We do find that firms in regulated industries are more likely to use nonfinancial performance measures $(p=0.09)$. Finally, we find some evidence that our proxy for the use of nonfinancial performance measures is negatively associated $(p=0.08)$ with firm age and positively associated $(p=0.06)$ with the length of the proxy statement discussion on executive compensation (we examine the determinants of DISCLOSE in more detail in the next section).

\subsection{Robustness Checks and Additional Evidence}

3.5.1. Alternative Measures of Employment Horizon. As a robustness check, we consider three alternative ways to model employment horizon concerns that are empirically less restrictive than our specification in (2). First, we separately include all of our proxies for short employment horizon instead of aggregating them in PR_TURN. We allow the slope coefficients of the employment horizon proxies to be different in highly profitable firms (allowing these coefficients to vary further across different groups of loss-making firms does not significantly improve fit of the model).

\footnotetext{
${ }^{7}$ This result is sensitive to the type of proxy we use for financial distress. The result in Table 2 relies on the Ohlson (1980) measure of bankruptcy as used in Ittner et al. (1997). We do not find a significant result when using proxies based on Altman (1968), revised Altman scores as in Begley et al. (1996), or market-based measures as in Hillegeist et al. (2004). Nevertheless, the evidence in Begley et al. (1996) supports the use of the Ohlson's model as the preferred measure of bankruptcy.
}

Table 3 Logit Estimation of the Likelihood of Using Nonfinancial Performance Measures in Annual Bonus Plans

\begin{tabular}{|c|c|c|c|c|c|c|}
\hline & \multicolumn{2}{|c|}{ NONFIN } & \multicolumn{2}{|c|}{ NONFIN } & \multicolumn{2}{|c|}{ NONFIN } \\
\hline & Coefficient & $p$-value & Coefficient & $p$-value & Coefficient & $p$-value \\
\hline Intercept & $-2.708^{*}$ & 0.071 & -2.290 & 0.149 & $-2.475^{*}$ & 0.092 \\
\hline PROF_L & 0.123 & 0.742 & 0.071 & 0.855 & & \\
\hline LOSS1 & 0.331 & 0.453 & 0.356 & 0.437 & & \\
\hline LOSS2 & 0.370 & 0.421 & 0.426 & 0.367 & & \\
\hline LOSS3 & $1.447^{* * *}$ & 0.003 & $1.535^{* * *}$ & 0.002 & & \\
\hline LOSS4 & $1.614^{* * *}$ & 0.002 & $1.799^{* * *}$ & 0.001 & & \\
\hline LOSS5 & $0.989^{* *}$ & 0.040 & & & & \\
\hline NLOSS & & & & & $0.265^{* * *}$ & 0.001 \\
\hline EARND & -0.082 & 0.414 & -0.048 & 0.663 & -0.060 & 0.539 \\
\hline$A G E$ & 0.162 & 0.613 & 0.307 & 0.366 & 0.144 & 0.641 \\
\hline AGE.PROF_H & -0.311 & 0.485 & -0.458 & 0.319 & -0.289 & 0.487 \\
\hline PSHO & $-0.189^{* *}$ & 0.034 & $-0.225^{* *}$ & 0.019 & $-0.185^{* *}$ & 0.034 \\
\hline PSHO.PROF_H & 0.103 & 0.389 & 0.155 & 0.213 & 0.097 & 0.411 \\
\hline CHAIR & 0.085 & 0.798 & 0.086 & 0.818 & 0.127 & 0.699 \\
\hline CHAIR.PROF_H & 0.245 & 0.682 & 0.257 & 0.681 & 0.185 & 0.752 \\
\hline FSTRESS & $-0.812^{* *}$ & 0.016 & $-0.784^{* *}$ & 0.026 & $-0.497^{*}$ & 0.071 \\
\hline MTB & -0.009 & 0.774 & -0.047 & 0.207 & -0.019 & 0.543 \\
\hline$R \& D S$ & $1.963^{* * *}$ & 0.008 & 0.546 & 0.676 & $1.779 * *$ & 0.015 \\
\hline EMPS & -3.536 & 0.593 & -18.269 & 0.210 & -4.442 & 0.503 \\
\hline CORR & $-1.049^{*}$ & 0.076 & $-1.767^{* * *}$ & 0.009 & $-1.209^{* *}$ & 0.038 \\
\hline STDM & 0.169 & 0.106 & $0.209^{*}$ & 0.068 & $0.197^{*}$ & 0.055 \\
\hline REGUL & 0.928 & 0.185 & 0.068 & 0.936 & 0.761 & 0.272 \\
\hline DISCLOSE & 0.269 & 0.217 & 0.202 & 0.381 & 0.242 & 0.258 \\
\hline FIRMAGE & -0.021 & 0.228 & -0.023 & 0.201 & -0.021 & 0.225 \\
\hline MSIZE & $0.115^{*}$ & 0.065 & $0.175^{* *}$ & 0.011 & $0.114^{*}$ & 0.066 \\
\hline Pseudo $R^{2}$ & 0.13 & & 0.12 & & 0.12 & \\
\hline Correctly classified & $67 \%$ & & $68 \%$ & & $67 \%$ & \\
\hline$N$ & 558 & & 500 & & 558 & \\
\hline
\end{tabular}

Notes. Industry dummies (three-digit SIC codes) used in a stepwise estimation procedure; SIC-382 and SIC-386 were retained as the only significant effects but not reported above. NLOSS, Number of consecutive loss years; $E A R N D$, number of earnings decreases during 1997-2001. Other variables are defined as in prior tables.

${ }^{* * *},{ }^{* *},{ }^{*}$ Significant at the $0.01 \%, 0.05 \%$, and $0.10 \%$ levels, respectively (two-tailed).

Moreover, we include an additional control variable counting the number of earnings decreases during 1997-2001 (EARND) to verify that our results are not primarily driven by earnings changes (rather than absolute losses). Second, we reestimate our results in a sample excluding firms with five consecutive loss years that we classified as start-ups rather than distressed firms (see Footnote 5). Third, we replace the dummy variables for the different types of loss firms with one variable counting the number of consecutive losses (NLOSS).

Overall, the results in Table 3 continue to be consistent with our theory. Incidental losses do not necessarily increase the likelihood of incorporating nonfinancial performance measures in annual bonuses. LOSS1 and LOSS2 firms who incur a loss for the first or second time after a series of profitable years are not more likely to use nonfinancial performance measures than are profitable firms. However, firms where losses are structural rather than incidental tend to adjust their incentive plans and 
include nonfinancial performance measures. In particular, firms with at least two prior losses before another loss in 2001 are much more likely to use nonfinancial performance measures than (highly) profitable firms.

A plausible interpretation of these results is that corporate boards are willing to redesign annual bonus plans only if there is a high likelihood that losses will persist in the future. This is consistent with prior literature suggesting that the number of consecutive loss years is associated with a higher likelihood of future losses (Joos and Plesko 2005). In contrast, earnings changes are much less persistent and thus less informative about future earnings, which may explain the insignificant effect of the number of earnings decreases during 1997-2001 (EARND). Similarly, we do not find a significant effect of an additional control variable counting how many times a firm missed analysts' annual earnings forecasts during 1997-2001. This additional control variable also leaves other findings in Table 3 qualitatively unchanged (untabulated results for a smaller sample where analysts' forecasts are available).

Among other proxies for employment horizon, only the percentage of shares owned by the CEO is significantly related to the use of nonfinancial performance measures. As predicted, $P S H O$, which reduces the likelihood of CEO turnover and thus increases employment horizon, is negatively associated with the use of nonfinancial performance measures. Interestingly, the effect of PSHO is not significant in highly profitable firms where entrenchment benefits of share ownership may be less important. We do not find a significant effect of CEO age and the CEO being a long-time chairman in either highly profitable or other types of firms.

Other major determinants of NONFIN in Equation (3) are largely consistent with our results in Table 2. As before, firm size and several of our proxies for informativeness of financial performance measures are significantly associated with the use of nonfinancial performance measures. It is noteworthy that the strong association between NONFIN and R\&D-to-sales ratios is driven by start-up (LOSS5) firms and is not significant after excluding them from the sample. Also, unlike the results in Table 2, we no longer find that firm age and length of proxy statement disclosures (DISCLOSE) are significantly associated with our proxy for the use of nonfinancial performance measures.

3.5.2. Equity Compensation. Firms where the CEO is likely to depart in the near future can address employment horizon issues and motivate long-term effort not only by increasing the emphasis on nonfinancial performance measures but possibly also by increasing the emphasis on stock-based compensation. Prior literature questions the efficiency of stock-based compensation in alleviating managerial myopia (McAnally et al. 2008, Erickson et al. 2006, Cheng and Warfield 2005). Nevertheless, we assess whether our results are robust to controlling for the importance of stock-based compensation. In particular, we reestimate our results in Tables 2 and 3, controlling for the relative proportion of equity in CEOs' total compensation, and find our results qualitatively unchanged. ${ }^{8}$

3.5.3. Length of Disclosure. We further recognize that NONFIN is an imperfect measure likely reflecting not only firms' emphasis on nonfinancial performance measures but also their choices regarding the detail of disclosures about executive compensation. To partially control for this effect, we collect data on the length (number of words) of proxy statement discussions of executive compensation (DISCLOSE) and include it in our regression models. We find evidence of a weak association between NONFIN and DISCLOSE in Table 2. To further assess potential biases due to varying levels of disclosures, we investigate in this section whether our groups of loss-making firms disclose systematically more about executive compensation than profitable firms.

We are aware of no prior study specifically examining the determinants of the length of proxy statement discussions of executive compensation. Without the guidance of prior literature, we specify a model of DISCLOSE similar to those estimated earlier and include proxies for (i) employment horizon, (ii) informativeness of financial performance measures, (iii) firm age and size, and (iv) the use of equity in CEO compensation packages in 2001. Table 4 presents the estimation results after removing some informativeness variables with no significant effect (given the lack of theoretical motivation, this improves parsimony and transparency of our final model). For ease of interpretation, the dependent variable in Table 4 is the raw (unlogged) number of words in the proxy statement discussion of executive compensation (the results are similar when DISCLOSE is logtransformed as before).

\footnotetext{
${ }^{8}$ We define the proportion of equity in total compensation as the sum of restricted stock granted and the aggregate value of all options granted during 2001 as reported in the proxy statement (item SOPTVAL in Execucomp whenever available) divided by the sum of total compensation including (in addition to equity compensation in the numerator) salary, bonus, long-term incentives, other annual compensation, and the amount under "all other compensation" in firms' proxy statements. Note that this measure reflects the relative importance of annual grants of equity incentives rather than portfolio equity incentives. Although we do not have data to construct a measure of portfolio incentives as in Core and Guay (1999) for all our sample firms, we find a high correlation $(p<0.01)$ between the Core and Guay measure of portfolio incentives and our measure of percentage of shares owned by the CEO (PSHO) for our sample firms with data available on Execucomp.
} 
Table 4 OLS Model of the Length of the Proxy Statement Discussion of Executive Compensation

\begin{tabular}{|c|c|c|}
\hline & \multicolumn{2}{|c|}{ DISCLOSE } \\
\hline & Coefficient & $p$-value \\
\hline Intercept & $532.7^{* * *}$ & 0.000 \\
\hline PROF_L & 3.6 & 0.952 \\
\hline LOSS1̄ & 105.5 & 0.126 \\
\hline LOSS2 & -21.0 & 0.777 \\
\hline LOSS3 & 115.1 & 0.139 \\
\hline LOSS4 & -22.8 & 0.778 \\
\hline LOSS5 & $221.0^{* * *}$ & 0.001 \\
\hline$A G E$ & 66.8 & 0.117 \\
\hline PSHO & $-59.7^{* * *}$ & 0.000 \\
\hline CHAIR & 34.6 & 0.487 \\
\hline FSTRESS & $142.2^{* *}$ & 0.011 \\
\hline REGUL & $225.7^{*}$ & 0.099 \\
\hline EQUITY & 45.2 & 0.252 \\
\hline FIRMAGE & 2.8 & 0.358 \\
\hline MSIZE & $66.0^{* * *}$ & 0.000 \\
\hline $\begin{array}{l}\text { Adj. } R^{2} \\
N\end{array}$ & & \\
\hline \multicolumn{3}{|c|}{$\begin{array}{l}\text { A10tes. DISCLOSE, Number of words in the proxy statement dis- } \\
\text { CuSsion of executive compensation; EQUITY, dummy variable equal } \\
\text { to one if CEO receives equity compensation. Other variables are } \\
\text { defined as in prior tables. Industry dummies (three-digit SIC codes) } \\
\text { were used in a stepwise estimation procedure; significant effects } \\
\text { were retained but not reported above. } \\
{ }^{* * *},{ }^{* *}, * \text { Significant at the } 0.01 \%, 0.05 \% \text {, and } 0.10 \% \text { levels, } \\
\text { respectively (two-tailed). }\end{array}$} \\
\hline
\end{tabular}

We find that compensation disclosures in start-up firms (LOSS5) are more detailed than in (highly) profitable firms. The estimated difference is 221 words and is highly significant $(p<0.01)$. LOSS1 and LOSS3 also disclose somewhat more than highly profitable firms - the differences are 105 words, $p<0.13$, and 115 words, $p<0.14$, respectively. In light of these results, it is unlikely that our finding in Table 3 that LOSS3 and LOSS4 use nonfinancial performance measures more than profitable firms is primarily driven by the length of disclosures. For LOSS5 firms, the results in Table 3 hold after controlling for DISCLOSE, which suggests that the result is robust to measurement biases that might arise because the use of nonfinancial performance measures is easier to detect in more detailed disclosures.

We further find that disclosures are more detailed when firms face financial distress (by about 142 words, $p=0.01)$ and when they operate in regulated industries (by 226 words, $p=0.10$ ). The remaining two (highly significant) predictors are firm size, which is positively associated with disclosure, and percentage of shares owned by the CEO, which is negatively associated with disclosure. Although outside the scope of this paper, the latter effect seems to suggest that entrenched CEOs are shielded from pressures to disclose more about their compensation.
3.5.4. Measuring the Use of Nonfinancial Measures. Finally, we assess robustness of our results to alternative coding of NONFIN. We consider two narrower definitions of the use of nonfinancial performance measures and reestimate the results in Tables 2 and 3. First, we reclassify all firms using individual performance measures as observations with NONFIN equal zero rather than one (as an alternative, we also exclude these observations). Second, we consider a narrow definition of NONFIN equaling one only if firms report the use of "nonfinancial" or "qualitative" measures or give an example of a performance measure that can unambiguously be classified as nonfinancial (as an alternative, we also exclude observations that do not meet this narrow definition). Our main finding that short employment horizon is associated with a greater use of nonfinancial performance measures continues to hold when using these alternative measures.

Overall, the evidence above alleviates concerns that our results are driven by measurement issues inherent in examining the use of nonfinancial performance measures based on publicly available data. However, we acknowledge that NONFIN remains an imperfect measure. In particular, firms that use nonfinancial performance measures for determining CEO bonuses may put a large or small weight on these measures, which is typically not disclosed, and thus is not captured by NONFIN. To address this limitation, the next section presents the results of tests using more detailed measures of the emphasis on nonfinancial performance measures albeit in a smaller sample.

\section{Field and Survey Data}

Our analysis in the previous section relies on publicly available data. Its main advantage is the large random sample of firms with different patterns of losses (profits). Inevitably, this comes at a cost of a less comprehensive measurement of the extent to which different firms rely on nonfinancial measures for performance evaluation. We examine to what extent this potential shortcoming affects our conclusions by collecting additional field and survey data. Even though this additional data sample is small and nonrandom, it allows us to triangulate the main findings by employing different data collection methods.

\subsection{Data Collection}

4.1.1. Field Data. We started by conducting field interviews in 12 loss-making entities purposely chosen to be highly diverse. ${ }^{9}$ The aim of these exploratory

\footnotetext{
${ }^{9}$ Seven of these entities were loss-making firms and five were lossmaking divisions. They varied significantly in size, age, ownership (public versus private), and industry. Online Appendix B in the e-companion contains additional information and detailed descriptions of eight of the most interesting loss situations.
} 
interviews was to improve our understanding of performance measurement issues in loss-making entities and to facilitate the survey stage of our research. We relied on the following insights from the field when constructing our measures for the main variables of interest.

First, we found that loss-making entities can emphasize nonfinancial performance measures in three different ways: (i) by placing more weight on nonfinancial measures in overall evaluations; (ii) by placing more weight on nonfinancial measures in bonus plan formulas; and (iii) by evaluating performance subjectively. This distinction reflects that annual bonuses are not the only performance-dependent rewards given, and the weights on performance measures included in annual bonus plan formulas are sometimes quite different from those used in the overall evaluation of managers' performances and in the assignments of other forms of rewards. The distinction also reflects that managers can leave the weights in performance evaluation formulas unchanged but increase the emphasis on subjective evaluation (e.g., Site 3 in Online Appendix B), which typically implies consideration of a wide range of factors (Gibbs et al. 2004).

Second, our field interviews helped us identify entities where managers' employment horizon is likely to be short. In particular, we found that loss-making entities expecting losses (i.e., entities where losses are likely to persist) tend to rely on nonfinancial performance measures more than loss-making entities expecting profits (i.e., entities that have been lossmaking but expect to turn profitable in the foreseeable future). This is consistent with our theory because returning to profitability should reduce the likelihood of managerial turnover and alleviate the employment horizon problem. In the words of a director of compensation (Site 6): "When a loss is more ${ }^{\mathbf{A} 11}$ 'structural,' as opposed to 'transitory,' I would reverse the order of incentive system priority; that is, I would place retention before motivation, and I would be sure to find ways to keep the long-term focus." Similar retention concerns were mentioned in six of the eight sites in Online Appendix B, and assigning incentives subjectively or linking them to nonfinancial performance measures "to keep the long-term focus" was identified as a remedy. This suggests that the importance of retention concerns could serve as another proxy for the severity of employment horizon issues.

Third, we identified several empirical proxies for informativeness of earnings and verified that they relate to the emphasis on nonfinancial performance measures as expected. In particular, we found that the emphasis on nonfinancial measures is higher when earnings are more noisy; that is, when they are adversely affected by uncontrollable events (Site 3), when performance targets are inaccurate (Site 6), or when poor information systems produce unreliable measures (Site 8). On the other hand, earnings are emphasized in entities where profit urgency is high (e.g., due to a struggle to survive or the need to finance long-term growth) or when there is a need for profit-enhancing actions by management (Sites 2 and 7).

4.1.2. Survey Data. In March 2005, we invited business school graduates of the Universities of Michigan and Southern California with a minimum of five years experience to participate in an online survey. Our initial email message stated that we sought participants informed about performance measurement and incentives of CEOs/managers of entities reporting losses in the prior three years. To have a control group, we also invited those informed about performance measurement and incentives of CEOs/managers in profitable entities to participate. We excluded respondents from (i) small entities defined as entities with sales lower than $\$ 10$ million and fewer than 50 employees and (ii) owner-managed or professional firms (e.g., accounting or consulting firms). After further excluding responses with missing values, we obtained our final sample of 141 entities, which is $33 \%$ of the number of respondents who were sent a link to our online survey. Our final sample consists of 74 loss-making and 67 profitable entities. About $60 \%$ of our sample consists of firm-level entities; the other $40 \%$ are divisions within firms. About $23 \%$ of the respondents are CEOs or general managers; $16 \%$ are CFOs or division controllers; $28 \%$ are corporate controllers, vice presidents, or directors; and the remaining 33\% include other respondents such as finance and human resource managers.

\subsection{Variable Measurement}

4.2.1. Emphasis on Nonfinancial Performance Measures. Our field study suggests that loss-making entities can emphasize nonfinancial performance measures in at least three different ways: (i) by placing more weight on nonfinancial measures in overall evaluations, (ii) by placing more weight on nonfinancial measures in bonus plan formulas, and (iii) by evaluating performance subjectively. Below, we describe how we measure each of these different manifestations of the emphasis on nonfinancial performance measures:

Weight on nonfinancial measures in overall evaluations (NONFIN_OV). We asked the respondents to ascribe relative weights $(0 \%-100 \%)$ to the following performance measures in overall performance evaluations (Question 1 in Online Appendix $C$ in the e-companion): bottom-line financial; other financial; nonfinancial; individual (e.g., leadership skills, ability to attract, and retain key personnel); and other 
performance measures. NONFIN_OV is the weight on nonfinancial and individual performance measures.

Weight on nonfinancial measures in bonus plan formulas (NONFIN_B). Question 2 lists the same performance measures as in NONFIN_OV; however, it specifically asks about 2004 bonuses as a percentage of salary earned for performance as measured by each of the items. NONFIN_B is the weight on nonfinancial and individual performance measures in bonus plans. ${ }^{10}$

Extent to which performance is evaluated subjectively (SUBJECT). Question 3 measures SUBJECT from the respondents' indication of the extent to which the evaluators relied on subjective evaluations as opposed to a formulaic performance evaluation approach $(0 \%-100 \%)$.

4.2.2. Employment Horizon. Our field study observation also helped us to identify entities where managers' employment horizon is likely to be short: (i) loss-making entities expecting losses to persist and (ii) entities concerned about retention of their managers. Thus, we use the following proxies for short employment horizon.

Types of loss-making entities. Questions 4 asked respondents to classify their entity as either a lossmaking start-up entity, other loss-making entity, or a profitable entity. ${ }^{11}$ In addition, respondents indicated using dummy variables whether their entity reported profits/losses in each of the years 2001-2004 and whether they expected a profit or loss in 2005. They also reported actual and budgeted earnings for 2004 and budgeted earnings for 2005. Based on this information, we categorize our sample entities into four mutually exclusive categories as follows.

Loss-making start-up entities (LOSS_ST) are described by respondents as being "in a start-up mode" (first two categories of Question 4). Although they may turn profitable in the near future, their prospects are likely uncertain, increasing the probability of voluntary or forced CEO departure and raising employment horizon issues (i.e., much like LOSS5 firms in our archival data).

Loss-making entities expecting losses (LOSS_EL) reported actual or budgeted losses in 2004 and 2005.

\footnotetext{
${ }^{10}$ NONFIN_B includes higher-level performance measures as an additional item because bonus plan formulas of division managers sometimes include measures of business group or firm performance. These are not included in NONFIN_OV, which relates to executive rather than entity performance. To allow for comparability of firm-level and division entities, we recalculate the relative weights in divisions so that they sum up to $100 \%$ when higher-level measures are excluded. NONFIN_B is the (recalculated) weight on nonfinancial and individual performance measures in bonus plans.

${ }^{11}$ Question 4 includes six categories, two for each of the three main groups. Due to limited sample size, however, we classify our sample entities into four groups only (start-up entities, loss-making entities expecting losses, loss-making entities expecting profits, and profitable entities).
}

Although losses in 2004 were reoccurring for most of these entities, for a few 2004 was their first loss year. At the time of designing their incentive schemes (the end of 2003 or the beginning of 2004), however, losses and potentially shorter employment horizons were likely anticipated in these entities.

Loss-making entities expecting profits (LOSS_EP) had at least two losses during 2001-2003 but turned profitable after that (actual and budgeted earnings in 2004 and budgeted earnings in 2005 were all positive). Employment horizon issues in this group are likely less severe than in other loss-making entities.

Profitable entities (PROF) are described by respondents as profitable (last two categories of Question 4) and they have actual and budgeted profits both in 2004 and 2005. This is our control group where we expect little or no employment horizon issues.

Retention concerns (RETAIN). Respondents estimated the relative importance $(0 \%-100 \%)$ of motivation and retention in the design of CEOs' or general managers' incentive compensation for 2004 (Question 5). We expect RETAIN, the weight on retention, to be increasing in employment horizon concerns.

4.2.3. Control Variables. When testing Hypothesis 1 , we need to control for congruence and noise in earnings and for other potentially confounding factors. Based on prior literature and our field observations, we control for congruence of earnings using a proxy for profit urgency that reflects the perceived pressure within an entity to deliver shortterm profits (Ittner et al. 1997, Gilson and Vetsuypens 1993). Further, we use multiple measures to proxy for noise in earnings - the presence of adverse uncontrollable factors, ex ante environmental uncertainty, and quality of the information systems (inversely related to noise), all of which we identified as important factors in the field phase of our study.

Profit urgency (URGENT). Respondents indicated on two 1-5 Likert scales the extent to which they agreed that "the entity has adequate (access to) capital for the near term" and "the entity faces strong pressures to earn short-term profits" (Question 6). Because each of these two items likely identifies settings where shortterm financial performance measures are crucial for survival and because both items are not significantly correlated, we code URGENT as a dummy variable equal to one if respondents "strongly disagree" with the former statement or "strongly agree" with the latter, thereby capturing that strong (dis)agreement with at least one of these items is indicative of profit urgency.

Adverse uncontrollable factors (UNCONTR). We measure the presence of adverse uncontrollable factors in an entity's environment based on self-reported $(0 \%-100 \%)$ measures of executive performance and entity performance (Question 7). We assume that 
whenever executive performance is much better than entity performance, it must be because entity performance was adversely affected by some uncontrollable factors. Thus, we code UNCONTR as a dummy variable equal to one if executive performance is greater than entity performance by $40 \%$ or more (other cutoffs yield similar results).

Environmental uncertainty. We measure ex ante environmental uncertainty with six 1-5 Likert scales (Question 8). Exploratory factor analysis of the six items revealed three underlying factors with the highest loadings on: (i) ETARGET, two items about accuracy of demand forecasts and ability to set meaningful annual performance targets; (ii) ECOMP, two items about competition for main products and predictability of competitors' actions; and (iii) ETECH, two items about the frequency of new product introductions and the degree of technological change.

Quality of information systems (ISYS). Respondents indicated on a 1-5 Likert scale the extent to which they agreed that "the entity's information systems are effective" (Question 9). High ISYS scores indicate agreement.

Finally, we also use two other variables to control for other potentially confounding factors: the natural logarithm of the number of employees (SIZE) and a dummy variable (PUBLIC) indicating whether an entity (or the firm the entity belongs to) is publicly listed.

\subsection{Descriptive Statistics}

The final sample of entities participating in our survey consists of 74 loss-making and 67 profitable entities. Among the loss-making entities, there are 48 lossmaking entities expecting losses, 13 loss-making entities expecting profits, and 13 loss-making start-up entities. The performance measurement and evaluation practices in our sample entities are highly varied. Combining all loss-making entities (untabulated), the average weight on nonfinancial performance measures is $38 \%$ in overall evaluations and $28 \%$ in bonus plan formulas; the average extent to which performance evaluation is subjective is $58 \%$. The averages in profitable entities are lower: $29 \%$ on nonfinancial performance measures in overall evaluations, $21 \%$ in bonus plan formulas, and $37 \%$ of performance evaluation is subjective.

Online Appendix A provides detailed descriptive statistics for each of the four different groups of entities. Briefly, the median number of employees ranges from 80 in start-up entities to 400, 450, and 600 in profitable, LOSS_EL, and LOSS_EP entities, respectively. Some of the most salient differences pertain to profit urgency, the presence of adverse uncontrollable factors, and the importance of retention concerns, all of which are considerably lower in profitable entities.
In addition, Online Appendix A presents a correlation table with the variables defined in the previous section. In the interest of brevity, we only note here that the three different proxies for the emphasis on nonfinancial performance measures are highly correlated.

\subsection{Results}

As discussed before, firms dealing with employment horizon issues can motivate long-term effort and emphasize nonfinancial aspects of performance in different ways. Our questionnaire survey takes that into consideration and collects detailed information on performance measurement practices in profitable and loss-making entities. Specifically, we examine how much weight our sample entities put on (i) nonfinancial performance measures in overall evaluations (NONFIN_OV), (ii) nonfinancial performance measures in annual bonus plans (NONFIN_B), and (iii) subjective (not formula-based) evaluations (SUB$J E C T$ ). We regress these three dependent variables on our proxies for short employment horizon, proxies for informativeness of financial performance measures, and controls for size and public listing:

$$
\begin{aligned}
\text { NONFIN_i } & \\
= & \theta_{0}+\theta_{1} \text { LOSS_EP }+\theta_{2} L O S S \_E L+\theta_{3} L O S S \_S T \\
& +\theta_{4} \text { RETAIN }+\theta_{5} \text { URGENT }+\theta_{6} \text { UNCONTROL } \\
& +\theta_{7} \text { ETARGET }+\theta_{8} E C O M P+\theta_{9} \text { ETECH }+\theta_{10} I S Y S \\
& +\theta_{11} \text { PUBLIC }+\theta_{12} \text { SIZE }+\zeta
\end{aligned}
$$

where NONFIN_ $i$ stands for NONFIN_OV, NONFIN_B, or SUBJECT. $\theta_{0}\left(\theta_{1}\right)$ represents the intercept for entities expecting to be profitable in the future that are currently profitable (loss-making). $\theta_{2}$ and $\theta_{3}$ are intercepts specific to loss-making entities expecting losses to persist and to start-up entities, where we expect greater CEO turnover and shorter employment horizons (based on our findings in Table 1; our survey data set does not contain turnover data to directly validate this). RETAIN reflects the relative importance of retention in the design of incentive compensation and serves as another proxy for short employment horizon. Thus, our main hypothesis predicts that $\theta_{2}, \theta_{3}$, and $\theta_{4}$ are positive.

Table 5 presents the results of estimating Equation (3). Overall, we find support for our main hypothesis. In most cases, our proxies for short employment are positively associated with the reliance on nonfinancial measures and subjectivity in performance evaluations. Specifically, the weight on nonfinancial performance measures in overall evaluations in lossmaking entities expecting losses and in start-up entities is greater than in profitable entities $(p=0.02$ and $p=0.03$, respectively). The weight is also increasing in the importance of retention concerns $(p=0.01)$. We 
Table 5 Tobit Models of the Weight on Nonfinancial Performance Measures as Reflected in Different Performance

Evaluation Practices

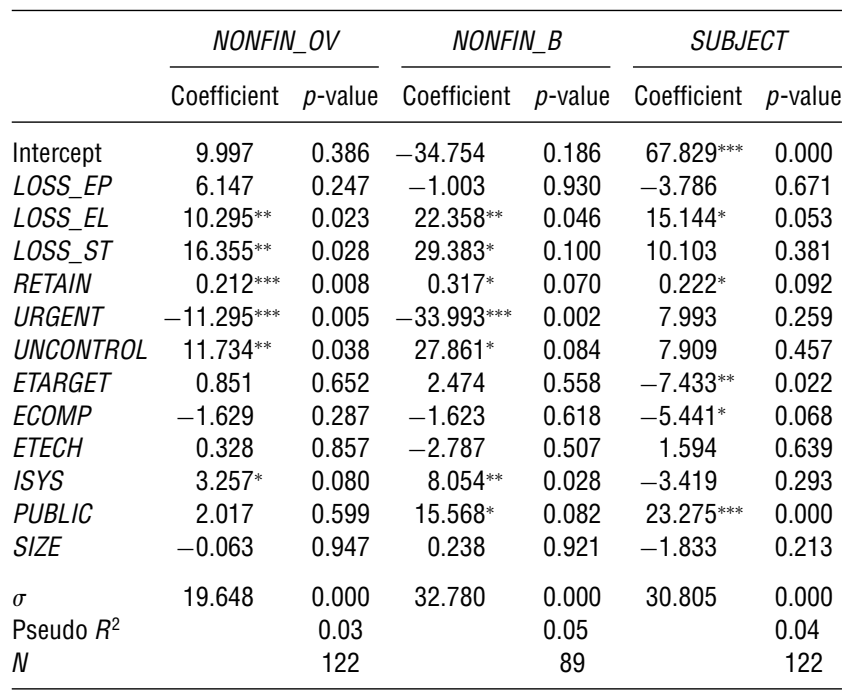

Notes. NONFIN_OV, Weight on nonfinancial performance measures in overall evaluations; NONFIN_B, weight on nonfinancial performance measures in bonus plan formulas; SUBJECT, the extent to which performance is evaluated subjectively; LOSS_EP, dummy variable for loss-making entities expecting profits both in 2004 and 2005; LOSS_EL, dummy variable for entities expecting losses in 2004 or 2005; LOSS_ST, dummy variable for loss-making startup entities. Other variables are defined in $\S 4.2$.

***, ${ }^{* *},{ }^{*}$ Significant at the $0.01 \%, 0.05 \%$, and $0.10 \%$ levels, respectively (two-tailed).

obtain similar results for the weight on nonfinancial performance measures in annual bonus plans and for subjectivity in performance evaluations (except that start-up entities are not significantly different from profitable entities regarding subjectivity). Finally, we note that loss-making entities that expect to turn profitable are not significantly different from profitable entities in any of the three regressions. This is consistent with our field study observation that the emphasis on nonfinancial performance measures is driven more by expected rather than actual earnings.

We also find partial support for the standard hypothesis that informativeness of financial performance measures is inversely proportional to the weight on other measures. Profit urgency, the absence of adverse uncontrollable factors, and target accuracy (all of which proxy for informativeness of financial performance measures) are negatively associated with the weight on nonfinancial performance measures in at least one of the regressions.

\section{Summary and Conclusions}

Our study collects field, survey, and archival data to examine how employment horizon issues affect the choice of performance measures in incentive contracts. We focus in particular on entities with persistent losses where managers are likely to voluntarily or forcibly depart in the near future. Relying on prior theoretical literature, we predict that entities where managerial employment horizon is short are more likely to emphasize forward-looking, nonfinancial performance measures. This is because an increased emphasis on nonfinancial performance measures encourages long-term effort and reduces the incentive of managers to myopically maximize short-term financial results before leaving the firm.

Our data from different sources consistently support this hypothesis. First, we find that our aggregate proxy for short employment horizon (based on an empirical model of the likelihood of CEO departure) is positively associated with the use of nonfinancial performance measures in annual bonus plans of 555 firms (Table 2). Further results in Table 3 show that nonfinancial performance measures are particularly common in loss-making firms with more than two consecutive losses where the CEO owns little stock (making turnover more likely). Second, we find that short employment horizon is significantly positively associated with three different proxies for high emphasis on nonfinancial performance measures in our survey sample of loss-making and profitable entities. In particular, loss-making entities expecting losses to persist and entities concerned about retention of their executives put greater weight on nonfinancial performance measures in overall evaluations and in bonus plan formulas, and also tend to evaluate performance in a more subjective manner. Overall, these findings provide robust support for the theory that the contracting value of forward-looking measures increases as managers' employment horizon becomes shorter.

Our analysis also adds to the discussion of how informativeness of earnings affects the choice of performance measures. Although it has been well established theoretically that the emphasis on forward-looking performance measures should be low when maximizing short-term financial goals is congruent with firm value, there is little empirical evidence to support this prediction. We find that profit urgency (e.g., due to financial distress) is associated with a substantially lower emphasis on nonfinancial performance measures in both our archival and survey data (Tables 2 and 5). In addition, we present several related results supporting the theory that informativeness of earnings is a major determinant of the use of nonfinancial performance measures.

Our findings are subject to some caveats. The archival data set relies on proxy statement disclosures as the only source of information on the choice of performance measures in annual bonus plans. Although we include a variable measuring the length of disclosure in our regressions, we acknowledge that disclosure choices cannot be completely controlled for in 
our analysis. For example, we cannot rule out the possibility that some firms use nonfinancial performance measures but do not disclose sufficient information in their proxy statements for us to categorize them correctly. Also, studying loss-making firms, many of which are in a preprofit stage or in financial distress, inevitably raises the issue of a survivorship bias. We acknowledge that our results, in particular those concerning our LOSS4 and LOSS5 groups, may only generalize to the population of loss-making firms that survive.

Regarding our additional data collection, we employed an anonymous online survey designed to be convenient for respondents to gain access to potentially sensitive information on performance measurement and evaluation practices in loss-making entities. This implies that our survey results are based on a relatively small nonrandom sample of entities. Also, space constraints on the online questionnaire did not allow us to fully establish reliability and validity of some of our empirical measures.

Notwithstanding these caveats, we find support for our hypothesis in different samples relying on different data collection methods. This provides reasonable assurance that our results are not driven by any of the data limitations discussed above.

\section{Electronic Companion}

An electronic companion to this paper is available as part of the online version that can be found at http:// mansci.journal.informs.org/.

\section{Acknowledgments}

The authors are grateful for financial support from the KPMG Foundation. They appreciate the comments from conference and workshop participants at the AAA 2006 Management Accounting Section Meeting, AAA 2005 Annual Meeting, EIASM 2004 Management Accounting Conference, KPMG-UIUC 2004 Business Measurement Research Workshop, Arizona State University, KU Leuven, London School of Economics, Manchester Business School, Tilburg University, University of Colorado at Boulder, University of Iowa, University of Michigan, and University of Southern California. They received helpful suggestions from the associate editor and two anonymous reviewers, as well as from Ramji Balakrishnan, Nerissa Brown, Clara Chen, Shijun Cheng, Paul Coram, Tony Davila, Patty Dechow, Michelle Hanlon, Rebecca Hann, David Huelsbeck, Raffi Indjejikian, Christo Karuna, Bill Lanen, Maria Ogneva, Steve Rock, Tatiana Sandino, and Frank Selto. They thank Housni El Maskoune, Sam Lee, Michael Minnis, Amish Patelad, Nemit Shroff, and Daniel Weimer for their able research assistance.

\section{References}

Altman, E. I. 1968. Financial ratios, discriminant analysis and prediction of corporate bankruptcy. J. Finance 23 589-609.
Baginski, S. P., J. M. Hassell, W. A. Hillison. 2000. Voluntary causal disclosures: Tendencies and capital market reaction. Rev. Quantitative Finance and Accounting 15 371-389.

Baker, G. 2000. The use of performance measures in incentive contracting. Amer. Econom. Rev. 90 415-420.

Balachandran, S. V. 2006. How does residual income affect investment? The role of prior performance measures. Management Sci. 52 383-394.

Banker, R. D., S. M. Datar. 1989. Sensitivity, precision, and linear aggregation of signals for performance evaluation. J. Accounting Res. 27 21-39.

Banker, R. D., G. Potter, D. Srinivasan. 2000. An empirical investigation of an incentive plan that includes nonfinancial performance measures. Accounting Rev. 75 65-92.

Begley, J., J. Ming, S. Watts. 1996. Bankruptcy classification errors in the 1980s: An empirical analysis of Altman's and Ohlson's models. Rev. Accounting Stud. 1 267-284.

Brickley, J. A., J. S. Linck, J. L. Coles. 1999. What happens to CEOs after they retire? New evidence on career concerns, horizon problems, and CEO incentives. J. Financial Econom. 52 341-377.

Bryan, S., L. Hwang, S. Lilien. 2000. CEO stock-based compensation: An empirical analysis of incentive intensity, relative mix, and economic determinants. J. Bus. 73 661-693.

Burgstahler, D., I. Dichev. 1997. Earnings management to avoid earnings decreases and losses. J. Accounting Econom. 24 99-126.

Chen, M. A. 2004. Executive option repricing, incentives, and retention. J. Finance 59 1167-1199.

Cheng, Q., T. A. Warfield. 2005. Equity incentives and earnings management. Accounting Rev. 80 441-476.

Cheng, S. J. 2004. R\&D expenditures and CEO compensation. Accounting Rev. 79 305-328.

Cheng, S. J., V. Nagar, M. V. Rajan. 2005. Identifying control motives in managerial ownership: Evidence from antitakeover legislation. Rev. Financial Stud. 18 637-672.

Core, J., W. Guay. 1999. The use of equity grants to manage optimal equity incentive levels. J. Accounting Econom. 28 151-184.

Datar, S., S. C. Kulp, R. A. Lambert. 2001. Balancing performance measures. J. Accounting Res. 39 75-92.

Dechow, P. M., R. G. Sloan. 1991. Executive incentives and the horizon problem: An empirical investigation. J. Accounting Econom. 14 51-89.

DeGeorge, F., J. Patel, R. Zeckhauser. 1999. Earnings management to exceed thresholds. J. Bus. 72 1-33.

Dikolli, S. S. 2001. Agent employment horizons and contracting demand for forward-looking performance measures. J. Accounting Res. 39 481-494.

Dikolli, S. S., I. Vaysman. 2006. Contracting on the stock price and forward-looking performance measures. Eur. Accounting Rev. 15 445-464.

Dikolli, S. S., S. C. Kulp, K. L. Sedatole. 2003. The role of CEO and investor horizons in the contracting use of forward-looking performance measures. Harvard NOM Research Paper 03-35, Harvard Business School, Boston.

Dutta, S., S. Reichelstein. 2002. Controlling investment decisions: Depreciation and capital charges. Rev. Accounting Stud. 7 253-281.

Dutta, S., S. Reichelstein. 2003. Leading indicator variables, performance measurement, and long-term versus short-term contracts. J. Accounting Res. 41 837-866.

Dutta, S., S. Reichelstein. 2005. Accrual accounting for performance evaluation. Rev. Accounting Stud. 10 527-552.

Engel, E., R. M. Hayes, X. Wang. 2003. CEO turnover and properties of accounting information. J. Accounting Econom. 36 197-226.

Erickson, M., M. Hanlon, E. L. Maydew. 2006. Is there a link between executive equity incentives and accounting fraud? J. Accounting Res. 44 113-143. 
Farrell, A. M., K. Kadous, K. L. Towry. 2008. Contracting on contemporaneous vs. forward-looking measures: An experimental investigation. Contemporary Accounting Res. 25.

Feltham, G. A., J. Xie. 1994. Performance measure congruity and diversity in multi-task principal-agent relations. Accounting Rev. 69 429-453.

Frost, C. A. 1997. Disclosure policy choices of UK firms receiving modified audit reports. J. Accounting Econom. 23 163-187.

Gaver, J. J., K. M. Gaver. 1998. The relation between nonrecurring accounting transactions and CEO cash compensation. Accounting Rev. 73 235-253.

Gibbons, R., K. J. Murphy. 1992. Optimal incentive contracts in the presence of career concerns: Theory and evidence. J. Political Econom. 100 468-505.

Gibbs, M., K. A. Merchant, W. A. Van der Stede, M. E. Vargus. 2004. Determinants and effects of subjectivity in incentives. Accounting Rev. 79 409-436.

Gilson, S. C., M. R. Vetsuypens. 1993. CEO compensation in financially-distressed firms: An empirical analysis. J. Finance 48 $425-458$.

Hayn, C. 1995. The information content of losses. J. Accounting Econom. 20 125-153.

Hillegeist, S. A., E. K. Keating, D. P. Cram, K. G. Lundstedt. 2004. Assessing the probability of bankruptcy. Rev. Accounting Stud. 9 5-34.

Huson, M. R., R. Parrino, L. T. Starks. 2001. Internal monitoring mechanisms and CEO turnover: A long-term perspective. J. Finance 56 2265-2297.

Hutton, A. P., G. S. Miller, D. J. Skinner. 2003. The role of supplementary statements with management earnings forecasts. J. Accounting Res. 41 867-890.

Ittner, C. D., D. F. Larcker, M. V. Rajan. 1997. The choice of performance measures in annual bonus contracts. Accounting Rev. 72 231-255.

Jensen, M. C., W. H. Meckling. 1992. Specific and general knowledge, and organizational structure. L. Werin, H. Wijkander, eds. Main Currents in Contract Economics. Blackwell, Oxford, UK. ${ }^{\text {. }}$

Joos, P., G. A. Plesko. 2005. Valuing loss firms. Accounting Rev. 80 847-870.

Lambert, R. A. 2001. Contracting theory and accounting. J. Accounting Econom. 32 3-87.
Lambert, R. A., D. F. Larcker. 1987. An analysis of the use of accounting and market measures of performance in executive compensation contracts. J. Accounting Res. 25 85-129.

Leone, A. J., J. S. Wu, J. L. Zimmerman. 2006. Asymmetric sensitivity of CEO cash compensation to stock returns. J. Accounting Econom. 42 167-192.

Lewellen, W., C. Loderer, K. Martin. 1987. Executive compensation and executive incentive problems-An empirical analysis. J. Accounting Econom. 9 287-310.

Li, F. 2008. Annual report readability, current earnings, and earnings persistence. J. Accounting Econom. 45 221-247.

McAnally, M. L., A. Srivastava, C. D. Weaver. 2008. Executive stock options, missed earnings targets, and earnings management. Accounting Rev. 83 185-216.

Miller, G. S. 2002. Earnings performance and discretionary disclosure. J. Accounting Res. 40 173-204.

Morck, R., A. Shleifer, R. W. Vishny. 1988. Management ownership and market valuation: An empirical analysis. J. Financial Econom. 20 293-315.

Nagar, V., M. V. Rajan. 2005. Measuring customer relationships: The case of the retail banking industry. Management Sci. 51 904-919.

Ohlson, J. A. 1980. Financial ratios and the probabilistic prediction of bankruptcy. J. Accounting Res. 18 109-131.

Rogers, J. L., P. C. Stocken. 2005. Credibility of management forecasts. Accounting Rev. 80 1233-1260.

Şabac, F. 2007. Dynamic agency with renegotiation and managerial tenure. Management Sci. 53 849-864.

Schrand, C. M., B. R. Walther. 2000. Strategic benchmarks in earnings announcements: The selective disclosure of prior-period earnings components. Accounting Rev. 75 151-177.

Skinner, D. J., E. Soltes. 2008. What do dividends tell us about earnings quality? Working paper, University of Chicago, Achicago.

Sliwka, D. 2002. On the use of nonfinancial performance measures in management compensation. J. Econom. Management Strategy 11 487-511.

Sloan, R. G. 1993. Accounting earnings and top executive compensation. J. Accounting Econom. 16 55-100.

Yermack, D. 1995. Do corporations award CEO stock-options effectively. J. Financial Econom. 39 237-269. 


\section{Author Queries}

A1 correct.

A2 Au: Keywords correct?

A3 Au: Confirm "2008” per reference list.

A4 variables. Please mark necessary changes throughout. Confirm/correct all changes.

A5

Au: Define IPO at first use.

A6 Au: Year correct?

A7 Au: No single asterisks appear in Table 1. Please check.

A8 Au: Last sentence of footnotes is unclear. Change to a complete sentence.

A9

A10

A10 Au: Confirm edits to all table footnotes are

correct.

A11

A12

A13

A14

Au: Quote correct? Reference available?

$\mathrm{Au}$ : Harvard business school correct?

$\mathrm{Au}$ : Add page numbers.

$14 \quad$ Au: Can reference be updated yet? 